\title{
Abundance of thraustochytrids and ciliated protozoans in a Mediterranean sandy shore determined by an improved, direct method
}

\author{
Giovanni Santangelo*, Lucia Bongiorni, Lucrezia Pignataro
}

Dipartimento Etologia, Ecologia, Evoluzione, Università di Pisa, Via Volta 6, 56126 Pisa, Italy

\begin{abstract}
Thraustochytrids (fungoid protoctists) and ciliated protozoans are major components of marine sandy shore microcommunities. However they are rarely enumerated together. This report describes the results obtained through application of an improved method for directly enumerating both of these microorganisms from sandy sediments. Thraustochytrids and ciliates were extracted by repeated washing with glutaraldehyde-seawater solution. To separate both microorganisms from non-living material the supernatant was centrifuged in a non-linear silica gel gradient, and then stained with 3 different fluorochromes. Sampling was carried out on a sheltered, medium-grain-sized sandy shore in the Ligurian Sea (NW Mediterranean). Ninety-six $1 \mathrm{ml}$ replicated sand samples were collected. They were arranged following a nested ANOVA design in which factors were 3 successively smaller spatial scales (sampling units of different size, ranging between meters and centimeters). Sampling was repeated 3 times during the autumn-winter period. Average ciliate abundance was $44 \pm 26 \mathrm{ml}^{-1}$, showing a significant decrease with time (from autumn to winter). The average abundance of thraustochytrids was $42.4 \pm 35.2 \mathrm{ml}^{-1}$, with no significant decrease over time. Neither group of protists showed a spatial structure at the scales explored. Variability among replicated $1 \mathrm{ml}$ samples was the main variance source for both microorganisms. The findings presented here are the first to address the distribution of thraustochytrids in marine sediments as determined by direct enumeration.
\end{abstract}

KEY WORDS: Thraustochytrids · Ciliates · Epifluorescence · Spatial distribution · Sandy shores · Mediterranean Sea

Resale or republication not permitted without written consent of the publisher

\section{INTRODUCTION}

Thraustochytrids are fungoid, Heterokonta protoctists (Cavalier Smith et al. 1994) common in marine and estuarine environments. These globular, saprobic organisms, ranging between 5 and $20 \mu \mathrm{m}$ in size, undergo asexual reproduction through biflagellate zoospores and are characterized by an ectoplasmic net that penetrates solid particles and absorbs organic matter (Porter 1990, Raghukumar 1996). Thraustochytrids can be isolated from various substrata and appear to be abundant in the sediments of coastal and estuarine environments

*E-mail: sant@deee.unipi.it
(Ulken 1981, Raghukumar \& Schaumann 1993, Bongiorni 1999). Such widespread occurrence, together with their ability to feed on diverse complex organic substrata, suggests that these organisms play an important ecological role within the microbial loop. Recently, higher biomass and $\mathrm{C} / \mathrm{N}$ ratios for thraustochytrids than for bacterioplankton were reported by Kimura et al. (1999), who concluded that thraustochytrids could play a more important role in the carbon cycle of marine ecosystems than has been previously recognized. Through degradation and decomposition, thraustochytrids promote the turnover of organic matter and establish trophic and competitive interactions with bacteria, ciliates and other protists. The biomass of thraus- 
tochytrids in detritus should be high enough to represent a significant food source for detritivores and ciliates (Fenchel 1980, Raghukumar \& Balasubramian 1991). Despite their likely ecological importance, these microorganisms are poorly understood because they cannot be preserved and stained directly in sediments, making the collection of quantitative data a trying task. To date, nearly all previous studies on thraustochytrid field distributions have relied upon techniques for culturing live samples mainly through the pine-pollen baiting method (Gaertner 1968). These culturing techniques clearly underestimate the actual numbers, as a direct method based on epifluorescence microscopy has recently yielded values some orders of magnitude higher (Raghukumar \& Schaumann 1993, Naganuma et al. 1998, Kimura et al. 1999).

Ciliated protozoa are among the main components making up the micro-communities in temperate, marine, medium- to fine-grained sandy shores (Fenchel 1967, Epstein 1997a, b). Dense ciliate populations, feeding on diatoms and other protists, should control their populations and, feeding on bacteria, promote bacterial mineralization processes in the sediment (Fenchel et al. 1998). Ciliates, in turn, are a significant food source for many suspension feeders (Ribes et al. 1998, 1999). Ciliate density in Mediterranean sandy shores may exceed several hundred cells $\mathrm{ml}^{-1}$ (Santangelo \& Lucchesi 1995).

Marine, interstitial ciliates have been the object of several quantitative studies based on direct counts, a partial review of which has been conducted by Finlay \& Fenchel (1996). Recently, attempts have been made to describe the community structure and spatial distribution pattern of ciliates in Mediterranean sandy shores (Lucchesi \& Santangelo 1995, 1997, Santangelo \& Lucchesi 1995). In those studies, ciliates were extracted from the sand following Uhlig's ice-water filtration method (Uhlig 1964), and live-sample counts were performed just after collection. Under these limiting conditions, a small number of replicated samples were examined. Only in recent years have ciliates been enumerated via fixation and staining by fluorochromes (Alongi 1993, Epstein 1995, 1997a,b, Tao \& Taghon 1997). In particular, Epstein (1995) has set forth a new method for enumerating all nano-, micro- and meiobenthos from marine sediments by extraction from glutaraldehyde-seawater washed sand samples and the separation from detritus by centrifugation in a nonlinear silica-gel gradient. In order to be counted efficiently, the fluorochrome-stained protists must be separated from sediment and detrital particles, which, due to background fluorescence, would mask them. This method enables extraction of nearly all ciliates from the sediment, and, by preserving them, also allows collection and examination of a higher number of samples, thus providing substantial quantitative data. According to Epstein (1995) this method collects nearly all nanobenthos and should therefore also be effective in isolating thraustochytrids. These fungi-protists were not identified by the protocol described by Epstein (1995) as it lacks a suitable staining procedure. A new method to directly identify thraustochytrids from several marine environments by fixing with formalin and staining them with acryflavine was developed by Raghukumar \& Schaumann (1993). This fluorescent dye stains thraustochytrid cells, revealing orange-to-red fluorescing multilayered cell walls and yellow-green fluorescing nuclei. It seemed worthwhile to design a protocol allowing for simultaneous fixation, extraction, separation from detritus, and staining of these 2 major components of the interstitial microcommunity.

The protocol, at once an improvement in and a compromise between those expounded by Raghukumar \& Schaumann (1993) for thraustochytrids and by Epstein (1995) for ciliates, allows a direct, reliable assessment of the abundance of both these protists. The thraustochytrid distribution in sandy sediments is completely unknown and that of ciliates is still only partly understood (Santangelo \& Lucchesi 1995, Jonsson \& Johansson 1997, Fenchel \& Blackburn 1999). Knowing the scale at which ecological processes operate is highly important to our understanding of such processes. Simple data on abundances of organisms, also new for some protists (as is the case of thraustochytrids), do not however furnish any information about the spatial structure of the populations examined. Such data reveal nothing about distribution gradients and patchiness (Underwood 1997). Thus, to tentatively explore the distribution of both microorganisms, samples were collected following a sampling design for nested ANOVA with 3 successively smaller spatial scales, i.e. sampling units of different size (Fig. 1). Nested sampling designs with different spatial scales should provide reasonably accurate information about the spatial structure and dynamics of sand bottom communities (Morrisey et al. 1992, Underwood 1997). The findings presented here are the first stemming from the direct enumeration and distribution analysis of thraustochytrids in sediment.

\section{MATERIALS AND METHODS}

Study area and sampling design. Sampling was carried out at Marina di Pisa $\left(43^{\circ} 42^{\prime} \mathrm{N}, 10^{\circ} 16^{\prime} \mathrm{E}\right)$, just south of the Arno river mouth, Tuscany, Ligurian Sea, Italy (Fig. 1), during the 1998-1999 autumn-winter season in October, November and January. An artificial breakwater with 2 small, north- and south-oriented passes sheltered the sandy shore. The sand was 


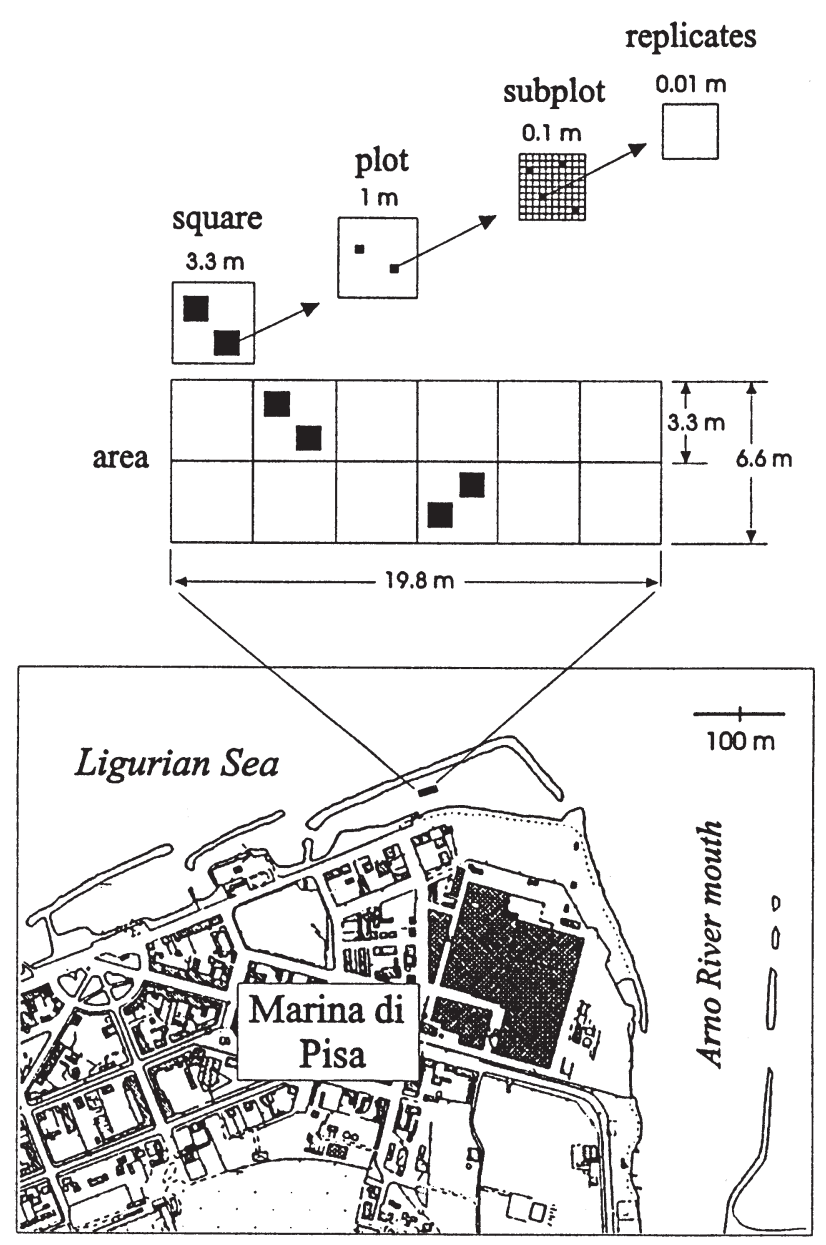

Fig. 1 Map of the sampling site and area in Marina di Pisa, Italy, showing the nested arrangement of the sampling units

medium-to-fine grained. Porosity ranged between 19.8 and $21.3 \%$, and total organic matter between 1.17 and $0.72 \%(\mathrm{w} / \mathrm{w} \%)$. Temperature and salinity ranged between 18 and $13^{\circ} \mathrm{C}$ and 34 and 36 psu respectively. Samples were collected during morning low tide in shallow water (0.30 to $0.40 \mathrm{~m}$ depth).

A $19.8 \times 6.6 \mathrm{~m}$ sandy area (Fig. 1) was divided into 12 $3.3 \times 3.3 \mathrm{~m}$ squares. Using a randomization program 2 squares were selected at each sampling from within the area. Each square then yielded random two $1 \times 1 \mathrm{~m}$ plots, and finally two $0.1 \times 0.1 \mathrm{~m}$ subplots were randomly selected per plot. Four replicate sand samples, $1 \mathrm{ml}( \pm 0.04 \mathrm{SE})$ each, were collected from each subplot by coring the sandy bottom with a glass tube to a depth of $1 \mathrm{~cm}$. Sampling was repeated at 3 different, randomly selected times. The nested factors were therefore: square, plot and subplot (with 2 levels each) with time as a fourth, 3-level random factor, hierarchical to the others.
Each collection yielded 32, $1 \mathrm{ml}$ sand replicated samples (replicates), for an overall number of 96. Replicates were processed as described in the following, and data of both thraustochytrid and ciliate density (cells $\mathrm{ml}^{-1}$ ) was then examined. The Cochran test was performed to assess variance homogeneity among samples, a basic assumption for ANOVA. As the test yielded significant results for ciliates, the data were log transformed and the test repeated. As the test results on log-transformed data were no longer significant, ANOVA was carried out on the transformed data (Underwood 1997).

Extraction, separation and staining of protists. Sand samples were fixed immediately after collection with $5 \mathrm{ml}$ glutaraldehyde-seawater solution $(1.5 \%$ final concentration) and kept cold. Glutaraldehyde fixation (Epstein 1995) was chosen over formalin fixation (Raghukumar \& Schauman 1993) because it is the only fixative compatible with Percoll and works with thraustochytrids as well as ciliates. Glutaraldehyde was diluted in filter-sterilized $(0.2 \mu \mathrm{m}$ pore size membrane) artificial seawater (particle-free seawater $=$ PFSW), kept at the same salinity as that measured in the field. The subsequent phases of the procedure are outlined in Fig. 2. Thraustochytrids and ciliates were extracted from each sample by gently hand washing/shaking them 4 times with $5 \mathrm{ml}$ of $1.5 \%$ glutaraldehyde-PFSW solution; each time the $5 \mathrm{ml}$ supernatant was collected yielding a total of $20 \mathrm{ml}$. A $4 \mathrm{ml}$ subsample of this $20 \mathrm{ml}$ of supernatant was then centrifuged. In this way $1 / 5$ of the original sample volume $(0.2$ of initial $1 \mathrm{ml})$ was processed. Epstein (1995) washed sandy samples 5 times with $6 \mathrm{ml}$ of glutaraldehyde-seawater solution, thus collecting $30 \mathrm{ml}$ supernatant of which $2 \mathrm{ml}$ subsamples were centrifuged (Epstein 1995), thereby processing only $1 / 15$ of the original sample volume (0.096 of initial $1.44 \mathrm{ml}$ ). According to Epstein (1995), this method enables extraction of over $90 \%$ of the nano- and over $95 \%$ of the microbenthos from sand samples. We chose to reduce both the number of washings (from 5 to 4 ) and the volume of the washing solution (from 6 to $5 \mathrm{ml}$ ) to reduce the dilution of original samples, achieving an extraction efficiency similar to that obtained by Epstein (1995).

The subsamples $(4 \mathrm{ml})$ were centrifuged in a nonlinear silica gel gradient (Percoll) at $5000 \times g$ for $15 \mathrm{~min}$ (the latter was prepared by centrifuging $12 \mathrm{ml}$ of a $50 \%$ PFSW-Percoll solution at $30000 \times g$ in a $18.5 \mathrm{ml}$ tube for $15 \mathrm{~min}$ ). As the uppermost fraction was never found to contain any ciliates or thraustochytrids, and the dense, lowermost layer held only detritus (undesired fluorescence source), these 2 layers were discarded $(0.5 \mathrm{~cm}$ thick each, for an overall volume of $1.54 \mathrm{ml}$ ). The remaining Percoll gradient was then vacuum filtered (35 $\mathrm{ml} \mathrm{Hg}$ ) on a black polycarbonate 

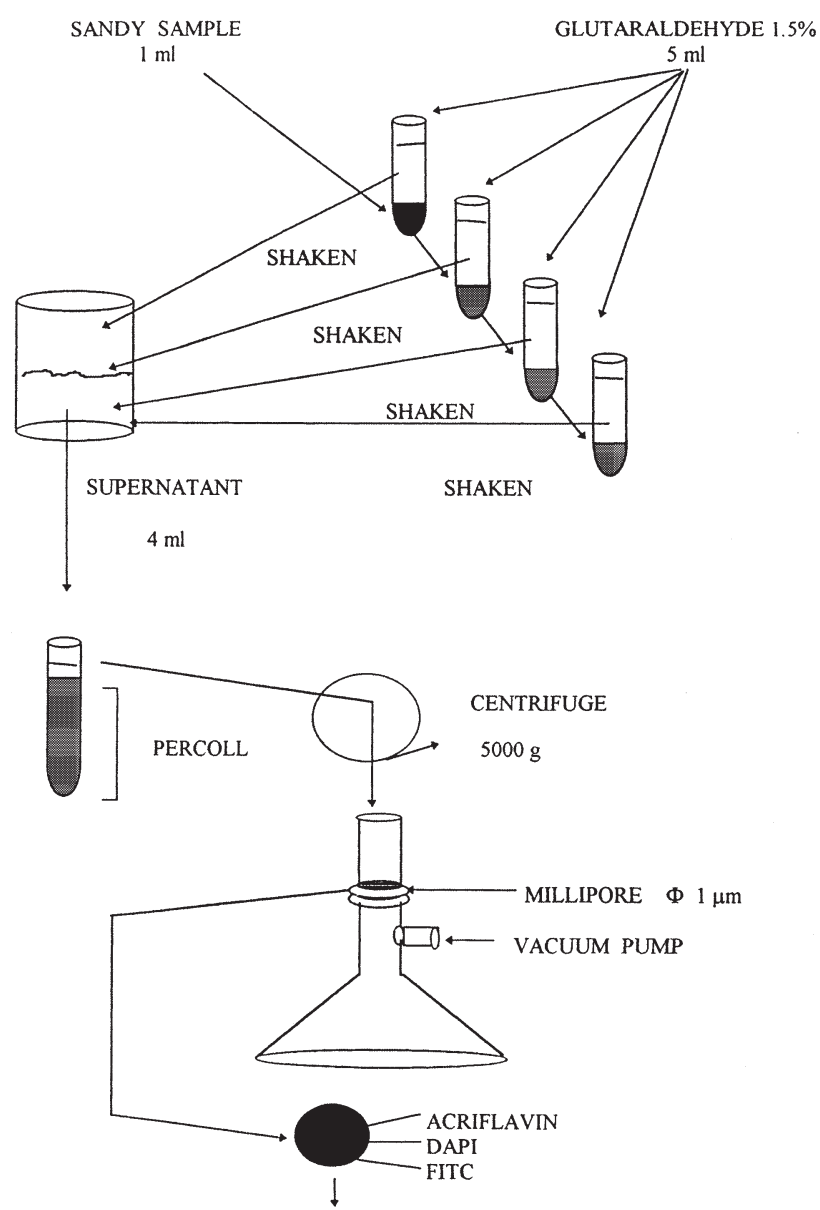

EPIFLUORESCENCE MICROSCOPE

Fig. 2. Method adopted to enumerate ciliates and thraustochytrids from marine sand samples. Samples were fixed and washed by glutaraldehyde-seawater solution, the supernatant was then centrifuged in a Percoll gradient, and the protists vacuum-concentrated on a millipore membrane and finally stained by fluorochromes

membrane (25 mm diameter, $1 \mu \mathrm{m}$ pore size, Poretics). The membranes with filtered material were then rinsed with PFSW, flooded with fluorochromes and vacuum drained again. Ciliates and thraustochytrids were stained consecutively with 3 fluorochromes: acriflavin hydrochloride (Sigma A-8251), DAPI (4', 6'diamino-2-phenylindole hydrochloride; Sigma D-9542) and FITC (fluorescein isothiocyanate; Sigma F-1522). The staining solutions were prepared as described in Raghukumar \& Shaumann (1993) for acriflavine and in Sherr et al. (1993) for DAPI and FITC. None of the fluorochromes interferes with another or has a jelling effect on Percoll.

The stains were vacuum drained after 4, 12 and 10 min, respectively, rinsed each time with PFSW and post-stained with $0.025 \%$ of the optical brightener
Calcofluor White (Sigma F6259) for 1 min. Each filter was placed on a microscope slide between 2 drops of immersion oil (Cargille type A) and examined under an epifluorescence microscope (Jena-Zeiss) equipped with a $50 \mathrm{~W}$ mercury lamp. A filter for DAPI (excitation filter $360 \mathrm{~nm}$, barrier filter $420 \mathrm{~nm}$ ) and one for acriflavine/FITC (excitation filter 450 to $490 \mathrm{~nm}$, barrier filter $520 \mathrm{~nm}$ ) were used.

According to Raghukumar \& Schaumann (1993), acriflavine simultaneously stains thraustochytrid sulphated polysaccharide cell walls red and their nuclei yellow-green, thus distinguishing these organisms from other similar-sized protoctists which fluoresce greenish only and lack red fluorescing cell walls. Finally, to distinguish thraustochytrids from other similar-sized photosynthetic protists, natural chlorophyll fluorescence was checked under UV excitation light: the photosynthetic protists were easily distinguished because of their peculiar red fluorescing cell content (Raghukumar \& Shaumann 1993).

Independent enumeration for ciliates and thraustochytrids was carried out on randomly selected halffractions of the polycarbonate membrane. Membranes were scanned at 100200 and 400×. The method was tested for efficiency on sterilized sand (collected in the sampling area) onto which known densities of pinepollen cultured thraustochytrids (Thraustochytrium motivum, Schizochytrium octosporeum) isolated in the same area (Bongiorni 1999) and lab cultured ciliates (Euplotes crassus, Euplotes minuta) had been dispersed. It is worth mentioning that the Euplotes species may be more resistant to this procedure than other ciliates (therefore yielding higher extraction efficiency) and that some ciliates (e.g. long, contractile Karyorelictida) are not well fixed with glutaraldehydeseawater solution. Moreover, many ciliates cannot be identified at high taxonomic level by this method.

\section{RESULTS AND DISCUSSION}

Extraction efficiency was checked by examining sterilized sand samples onto which known densities of cultured thraustochytrids and ciliates had been dispersed. A nearly complete recovery of both protists was achieved.

As the method allows for sample preservation, we were able to examine a high number of replicated samples and follow an ANOVA sampling design in which different spatial scales (sampling units of different size) were included. The abundance values for thraustochytrids are reported in Fig. 3A. Abundance in field samples ranged between 10 and 170 cells ml ${ }^{-1}$ and the average was $42.4 \pm 35.2$ cells $\mathrm{ml}^{-1}$, which according to previous estimations (Naganuma et al. 

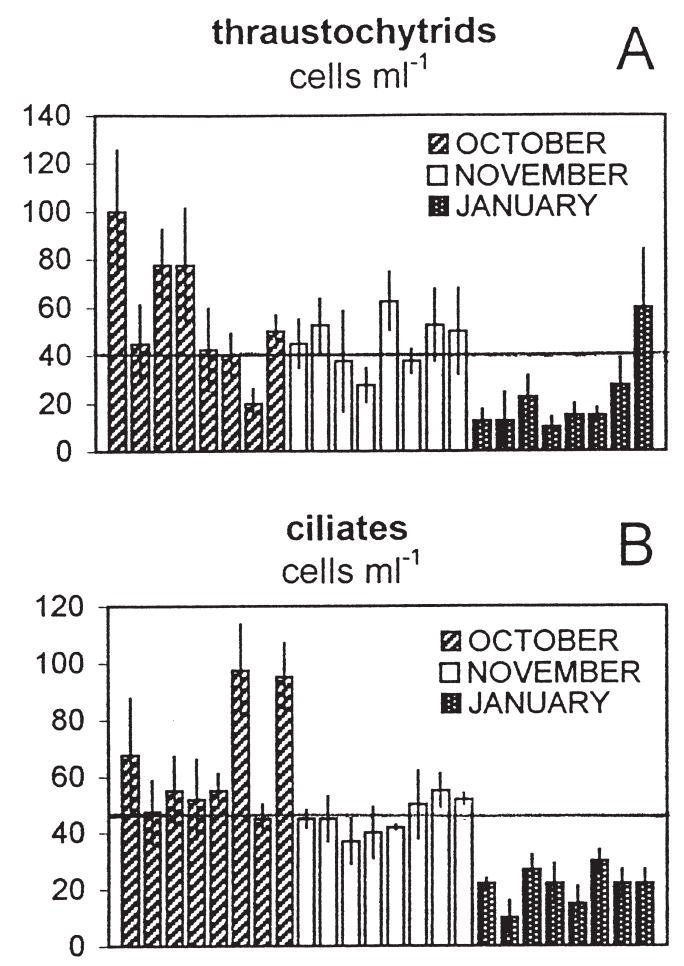

Fig. 3. (A) Average density $( \pm \mathrm{SE})$ of thraustochytrids in the different subplots (each composed by 4 replicated samples); (B) average density $( \pm \mathrm{SE})$ of ciliates in the different subplots (each composed by 4 replicated samples). Lines indicate overall average
1998, Kimura et al. 1999) corresponds to the biovolume of $22.200 \mathrm{\mu m}^{3} \mathrm{ml}^{-1}$ and an average biomass of $7000 \mathrm{pg}$ $\mathrm{C} \mathrm{ml}^{-1}$. Average October, November and January abundances were, respectively, $59.3 \pm 41.9,45.6 \pm 26.1$ and $21.9 \pm 25.2$ cells $\mathrm{ml}^{-1}$. On the basis of nested ANOVA, no significant difference in thraustochytrid abundance exists between either the different spatial scales or time of sampling (Table 1). The main variance components (hereafter expressed as \% of the overall variance) were those of residual (56.87\%) and time $(24.67 \%)$. The variance components of all 3 spatial factors, mainly those of plot and subplot, were extremely low (Table 1).

The abundances of ciliates in the different samples are reported in Fig. 3B. Their average abundance was $44 \pm 26$ cells $\mathrm{ml}^{-1}$, ranging between 10 and 130 cells $\mathrm{ml}^{-1}$. Such abundances are comparable with those previously assessed in Mediterranean sandy shores of the same geographic area during autumn-winter, which is characterized by a remarkably lower ciliate density than spring-summer and by a random distribution of these protists (Lucchesi \& Santangelo 1995).

The average estimated biovolume of ciliates was $9 \times$ $10^{5} \mathrm{\mu m}^{3} \mathrm{ml}^{-1}$, corresponding to a biomass of $13 \times 10^{4} \mathrm{pg}$ $\mathrm{C} \mathrm{ml}^{-1}$ (Putt \& Stoeckter 1989). On the basis of multifactorial ANOVA (Table 2), time was the only significant factor ( $p=0.014)$, due to a remarkable decrease in abundance from autumn to winter (October $64.2 \pm$ 30.3, November $45.9 \pm 15.6$ and January $21 \pm 11.1$ cells

Table 1. Multifactorial ANOVA calculated for thraustochytrid densities. Nested factors: Square (S), Plot (P), Subplot; orthogonal, random factor: Time (T) with 3 levels. No factor was significant. The main variance components (\%) are those of residual and time. Cochran test: not significant (no data transformation)

\begin{tabular}{|lrrrrrr|}
\hline Source of variation & df & \multicolumn{1}{c}{ SS } & $F$ & $p$ & F vs & \% variance components \\
\hline Time & 2 & 11.96 & 3.56 & 0.16 & $\mathrm{~S}(\mathrm{TI})$ & 24.67 \\
Square (T) & 3 & 5.04 & 3.44 & 0.93 & $\mathrm{P}[\mathrm{T}(\mathrm{S})]$ & 13.62 \\
Plot [T(S)] & 6 & 2.93 & 1.63 & 0.22 & $\mathrm{~S}\{\mathrm{~T}[\mathrm{~S}(\mathrm{P})]\}$ & 4.42 \\
Subplot $\{\mathrm{T}[\mathrm{S}(\mathrm{P})]\}$ & 12 & 3.59 & 0.97 & 0.49 & Residual & 0.41 \\
Residual & 72 & 22.24 & & & \\
Total & 95 & 45.78 & & & & 56.87 \\
\hline
\end{tabular}

Table 2. Multifactorial ANOVA calculated for ciliate densities. Nested factors: Square (S), Plot (P), Subplot; orthogonal and random factor: Time (T) with 3 levels. The only significant factor was Time. The main variance components (\%) are those of residual and time. Cochran test: significant. Data transformation: $\log E(x+1) ; C=0.139, \mathrm{p}>0.05$

\begin{tabular}{|lcccccr|}
\hline Source of variation & df & SS & $F$ & $p$ & F vs & \% variance components \\
\hline Time & 2 & 12.66 & 24.30 & 0.014 & $\mathrm{~S}(\mathrm{TI})$ & 40.5 \\
Square (T) & 3 & 0.78 & 2.41 & 0.163 & $\mathrm{P}[\mathrm{T}(\mathrm{A})]$ & 2.1 \\
Plot [T(S)] & 6 & 0.65 & 0.43 & 0.843 & $\mathrm{~S}\{\mathrm{~T}[\mathrm{~A}(\mathrm{P})]\}$ & 3.9 \\
Subplot $\{\mathrm{T}[\mathrm{S}(\mathrm{P})]\}$ & 12 & 3 & 1.74 & 0.076 & Residual & 0.1 \\
Residual & 72 & 10.37 & & & & 53.6 \\
Total & 95 & 27.46 & & & & \\
\hline
\end{tabular}


$\mathrm{ml}^{-1}$ ). Also in this case the main variance components were those of residual (53.6\%) and time (40.5\%) while variance components of all spatial factors examined (square, plot, subplot) were low.

As the frequency distribution of both protists was nearly normal, the relationship between their abundances was tested by examining the Pearson (parametric) linear correlation coefficient. The weak positive relationship found $(\mathrm{r}=0.24, \mathrm{n}=96, \mathrm{p}<0.02)$ indicates that the abundances of the 2 groups of protists are weakly linked in the environment and at the time interval examined. Both positive and negative correlations may stem from 2 synchronously oscillating variables, such as predator and prey densities, and would depend on the phase lag and the phase that was current during measurements (Naganuma et al. 1998).

In conclusion, our protocol, while allowing a somewhat limited resolution of ciliate taxonomic groups, does permit enumeration of both thraustochytrids and ciliates directly from a single preserved sediment sample and on the same filter. Thraustochytrids in particular, which are particle-associated, are efficiently separated from detritus and selectively stained. The method's main limitation is that it may be inappropriate for the smallest thraustochytrids, because of their tiny cell wall, or for most thraustochytrid zoospores, as these lack cell walls. The densities reported here should therefore be considered underestimates. No published work on direct enumeration of benthic thraustochytrids is available, so no comparison can be made between these and similar data. The benthic thraustochytrid densities found are the highest reported so far: they are about twice those estimated by the pine-pollen baiting, indirect method on benthic sand samples collected in the same area and season (Bongiorni 1999) and 3 times higher than those measured by direct, acriflavine-staining methods in summer coastal plankton from the Sea of Japan (Kimura et al. 1999). In light of the thraustochytrid's peculiarities, the non-negligible density revealed (slightly lower than that of the ciliates) suggests that these protists should be an important component of marine, coastal, interstitial microcommunities.

Thraustochytrids, by means of extensive ectoplasmic nets and highly degrading enzymes, penetrate refractory substrates such as cellulose cell walls of plants and play an important role in degradation of macrophyteproduced organic macromolecules (Ulken 1981). Moreover, although their density was several orders of magnitude lower than that of benthic bacteria, thraustochytrids have a carbon/cell volume content 3 and 2 times higher than that commonly assumed for bacteria (Kimura et al. 1999) and ciliates (i.e. Putt \& Stoecker 1989) respectively. In addition, they were recently found to contain high levels of polyunsaturated fatty acids (PUFAs) (Kimura et al. 1999). Thraustochytrids should provide a further source of essential fatty acids, which are not synthesized by bacteria nor by animals, to their consumers, such as amoebae, ciliates, filter feeders, detritivores, and larvae of invertebrates and vertebrates (Ulken 1981, Raghukumar 1986, Raghukumar \& Balasubramian 1991, Zhukova \& Kharlamenko 1999). This additional PUFA source may be extremely important in the microbial loop.

No variability in abundance was found at any of the different spatial scales explored for either protist, and the main variance component was residual. In other words, at that time and at the spatial scales examined, no spatial structure was found in the sampled area and the major differences in density were those between $1 \mathrm{ml}$ replicated sand samples, regardless of the distances between which they were collected. Such a finding could be due to the time at which samples were collected: during autumn and winter, hydrodynamic disturbance may inhibit patchiness of protists (Santangelo \& Lucchesi 1995). Clearly, protists could show some patchiness at a spatial scale smaller than those examined.

Some differences in the trend over time of ciliate and thraustochytrid abundance were found. In contrast with thraustochytrids, ciliates showed a significant decrease from autumn to winter, varying with temperature. Ciliates are thought to be predators of thraustochytrids (Fenchel 1980, Raghukumar 1996, Raghukumar \& Balasubramian 1991, Bongiorni 1999). As some degree of correlation between the densities of the 2 protists was found in the field, this hypothesis is strengthened.

Acknowledgements. We wish to thank S. Epstein for his suggestions on improving the sample processing protocol, S. Raghukumar for his useful comments on the text, J. A. Underwood for his help in analyzing the results of the ANOVAs, M. Nigro for the epifluorescence microscope facilities and A. Cafazzo for his revision of the English. This research was supported by the Italian National Council for Research (CNR), Project 03642.5774, 1998-1999.

\section{LITERATURE CITED}

Alongi DM (1993) Extraction of protists in aquatic sediments via density gradient centrifugation. In: Kemp PF, Sherr BF, Sherr EB, Cole JJ (eds) Aquatic microbial. ecology. Lewis Publishers, Boca Raton, p 109-114

Bongiorni L (1999) Ecology of thraustochytrids (fungilike marine protists) from Mediterranean coasts and their secondary metabolites production. PhD thesis, University of Pisa (in Italian)

Cavalier Smith T, Allsopp MT, Chao EE (1994) Thraustochytrids are chromists, not fungi: 18s rRNA signature of Heterokonta. Phil Trans R Soc Lond Ser B 346:378-397

Epstein SS (1995) Simultaneous enumeration of protozoa and micrometazoa from marine sandy sediments. Aquat Microb Ecol 9:219-227 
Epstein SS (1997a) Microbial food webs in marine sediments. I. Trophic interactions and grazing rates in two tidal flat communities. Microb Ecol 34:188-198

Epstein SS (1997b) Microbial food webs in marine sediments. II. Seasonal changes in trophic interactions in sandy tidal flat communities. Microb Ecol 34:188-198

Fenchel T (1967) The ecology of marine microbenthos. I. The quantitative importance of ciliates as compared with metazoans in various types of sediments. Ophelia 4:121-137

Fenchel T (1980) Relation between particle size selection and clearance in suspension-feeding ciliates. Limnol Oceanogr 25:733-738

Fenchel T, Blackburn N (1999) Motile chemosensory behaviour of phagotrophic protists: mechanisms for and efficiency in congregating at food patches. Protist 150: 325-336

Fenchel T, King GM, Blackburn TH (1998) Bacteria biogeochemestry: the ecophysiology of mineral cycling. Academic Press, San Diego

Finlay BJ, Fenchel T (1996) Ecology: role of ciliates in the natural environment. In: Hausmann $\mathrm{K}$, Bradbury P (eds) Ciliates cells as organisms. Fisher Verlag, Stuttgart, p 417-440

Gaertner A (1968) Eine Methode des quantitativen Nachweises niederer, mit Pollen koderbarer Pilze im Meervasser und im Sediment. Veröff Insti Meereforsch Bremerh 10:159-165

Jonsson PR, Johansson M (1997) Swimming behaviour, patch exploitation and dispersal capacity of a marine benthic ciliate in a flume flow. J Exp Mar Biol Ecol 215:135-153

Kimura H, Tatsuhiro F, Naganuma $T$ (1999) Biomass of thraustochytrid protoctists in coastal water. Mar Ecol Prog Ser 189:27-33

Lucchesi P, Santangelo G (1995) Time behaviour of marine ciliated protozoa of sandy shores. In: Eleftheriou A, Ansell $\mathrm{AD}$, Smith CJ (eds) Biology and ecology of shallow coastal waters. 28th Eur Mar Biol Symp. Olsen \& Olsen, Fredensborg, p 123-128

Lucchesi P, Santangelo G (1997) The interstitial cilate microcommunity of a Mediterranean sandy shore under differing hydrodynamic disturbances. Ital J Zool 64:253-259

Morrisey, DJ, Howitt A, Underwood AJ, Stark JS (1992) Spatial variation in soft-sediment benthos. Mar Ecol Prog Ser 81:197-204

Naganuma T, Takasugi H, Kimura H (1998) Abundance of thraustochytrids in coastal plancton. Mar Ecol Prog Ser 162:105-110

Editorial responsibility: John Dolan,

Villefranche-sur-Mer, France
Porter D (1990) Labyrinthulomycota. In: Margulis L, Corliss JO, Melkonian M, Chapman D (eds) Handbook of Protoctista. Jones \& Bartlett, Boston, p 388-398

Putt M, Stoecker DK (1989) An experimentally determined carbon:volume ratio for marine 'oligotrichous' ciliates from estuarine and coastal waters. Limnol Oceanogr 34: 1097-1103

Raghukumar S (1996) Morphology, taxonomy and ecology of thraustochytrids and Labyrinthulids, the marine counterparts zoosporic fungi. In Dayal MD (ed) Advances in zoosporic fungi. Publications PVT Ltd, New Delhi, p 35-60

Raghukumar S, Balasubramian R (1991) Occurrence of thraustochytrid fungi in corals and coral mucus. Indian J Mar Sci 20:176-181

Raghukumar S, Schaumann K (1993) An epifluorescence microscope method for direct detection of and enumeration of the fungilike marine protists: the thraustochytrids. Limnol Oceanogr 38(1):182-187

Ribes M, Coma R, Gili JM (1998) Heterotrophic feeding by gorgonian corals with symbiotic zooxanthellae. Limnol Oceanogr 43:1170-1179

Ribes M, Coma R, Gili JM (1999) Natural diet and grazing rate of the temperate sponge Dysidea avara through an annual cycle. Mar Ecol Prog Ser 176:179-190

Santangelo G, Lucchesi P (1995) Spatial distribution pattern of ciliated protozoa in a Mediterranean interstitial environment. Aquat Microb Ecol 9:47-54

Sherr EB, Caron DA, Sherr BF (1993) Staining of heterotrophic protists for visualization via epifluorescence microscopy. In: Kemp PF, Sherr BF, Sherr EB, Cole JJ (eds) Aquatic microbial ecology. Lewis PubLishers, Boca Raton, p 213-227

Tao SF, Taghon GL (1997) Enumeration of protozoa and bacteria in muddy sediment. Microb Ecol 33:144-148

Uhlig G (1964) Eine einfache Methode zur Extraction der vagilen, mesopsammalen Microfauna. Helgol Wiss Meeresunters 11:178-185

Ulken A (1981) On the role of phycomycetes in the food web of different mangrove swamps with brackish waters and waters of high salinity. Kiel Meeresforch Sonderh 5: $425-428$

Underwood JA (1997) Experiments in ecology. Cambridge University Press, Cambridge

Zhukova NV, Kharlamenko VI (1999) Sources of essential fatty acids in the marine microbial loop. Aquat Microb Ecol 17:153-157

Submitted: June 2, 2000; Accepted: November 6, 2000

Proofs received from author(s): November 28, 2000 